\title{
O imaginário da promoção da saúde no quotidiano das famílias na atenção primária
}

The Imaginary of Health Promotion in the everyday life of families in Primary Care

El imaginario de la promoción de la salud en la vida cotidiana de las familias en atención primaria.

\section{Juliana Chaves Costa ${ }^{\mathrm{I}}$, Rosane Goncalves Nitschke ${ }^{\mathrm{II}}$, Patrícia Fernandes Albeirice da Rocha $^{\mathrm{III}}$, Betina Barbedo Andrade ${ }^{\mathrm{IV}}$}

\begin{abstract}
RESUMO: Objetivo: conhecer o imaginário da Promoção da Saúde das famílias no quotidiano da Atenção Primária à Saúde. Método: estudo qualitativo, descritivo e exploratório, realizado de agosto a novembro de 2015 em um município no sul do Brasil, à luz do referencial da Sociologia Compreensiva e Quotidiano de Maffesoli. Os dados foram coletados através de entrevistas semiestruturadas, com 19 participantes e analisados de acordo com Schatzman e Strauss. Resultados: emergiram quatro categorias: Buscar saúde no quotidiano; Priorizar e Promover uma melhor qualidade de vida; Fragilidades da promoção da saúde no quotidiano do Sistema Único de Saúde (SUS); Potencialidades da promoção da saúde no quotidiano do SUS. Considerações finais: os participantes apontam a mudança de comportamento e não expandem as questões de saúde para além do setor saúde e de um estilo de vida. Porém, ressaltam a vontade de se manifestar em busca de direitos, enquanto cidadãos e usuários do SUS.
\end{abstract}

Descritores: Atividades cotidianas; Promoção da saúde; Atenção primária à saúde

\begin{abstract}
Objective: to know the imaginary of Health Promotion of families in the Primary Health Care routine. Method: a qualitative, descriptive and exploratory study, conducted from August to November 2015 in a municipality in southern Brazil, in the light of the Comprehensive Sociology and Everyday Life of Maffesoli. Data were collected through semi-structured interviews with 19 participants and analyzed according to Schatzman and Strauss. Results: four categories emerged: Seeking health in daily life; Prioritize and Promote a better quality of life; Weaknesses of health promotion in the daily life of the Unified Health System (SUS); Potentialities of health promotion in SUS routine. Final Considerations: Participants point to behavior change and do not expand health
\end{abstract}

\footnotetext{
${ }^{\mathrm{I}}$ Enfermeira. Mestra em Enfermagem pela Universidade Federal de Santa Catarina (UFSC). Docente do Centro Universitário Avantis. Balneário Camboriú, SC, Brasil. E-mail: julianachavescosta@gmail.com. ORCID: https://orcid.org/0000-0001-9311-1954

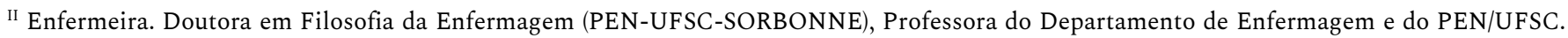
Líder do Núcleo de Pesquisa e Estudos em Enfermagem, Quotidiano, Imaginário, Saúde e Família de Santa Catarina (NUPEQUISFAM-SC). Florianópolis, SC, Brasil. E-mail: rosanenitschke@gmail.com. ORCID: https://orcid.org/0000-0002-1963-907X

${ }^{\text {III }}$ Enfermeira. Mestra em Enfermagem pela Universidade Federal de Santa Catarina (UFSC). Docente de Enfermagem no IFSC. Joinville, SC, Brasil. E-mail: patricia.albeirice@ifsc.edu.br. ORCID: https://orcid.org/0000-0002-7319-9220

IV Enfermeira. Doutora em Saúde e Desenvolvimento na Região Centro-Oeste pela Universidade Federal de Mato Grosso do Sul. Docente de Enfermagem no IFSC. Joinville, SC, Brasil. E-mail: betina.barbedo@ifsc.edu.br. ORCID: https://orcid.org/0000-0003-1816-5447.
} 
issues beyond the health sector and lifestyle. However, they emphasize the desire to urge themselves in search of rights, as citizens and users of SUS.

Descriptors: Activities of Daily Living; Health Promotion; Primary Health Care.

Resumen: Objetivo: conocer el imaginario de la promoción de la salud de las familias en rutina de la atención primaria de salud. Método: estudio cualitativo, descriptivo y exploratorio, realizado de agosto a noviembre de 2015 en un municipio del sur de Brasil, a la luz de la Sociología de la comprensión y cotidiana de Maffesoli. Los datos fueron recogidos a través de entrevistas y analizados de acuerdo con Schatzman y Strauss. Resultados: surgieron cuatro categorías: búsqueda de salud en la vida diaria; Priorizar y promover una mejor calidad de vida; Debilidades de la promoción de la salud en la vida diaria del Sistema Único de Salud (SUS); Potencialidades de la promoción de la salud en la vida diaria del SUS. Consideraciones finales: los participantes señalan un cambio de comportamiento y enfatizan el deseo de manifestarse en busca de derechos, como ciudadanos y usuarios del SUS.

Descriptores: Actividades Cotidianas; Promoción de la Salud; Atención Primaria de Salud

\section{Introdução}

A Promoção da Saúde surge como marco norteador das mudanças paradigmáticas em relação à saúde individual e coletiva do século XX. Este conceito mais abrangente veio com maior impacto após a Carta de Ottawa, no ano de 1986, por compreender saúde num contexto complexo e ter enquanto recursos condicionantes: paz, habitação, educação, alimentação, renda, ecossistema estável, recursos sustentáveis, justiça social e equidade. ${ }^{1}$

Estudos iniciados por Frederich Engels e Rudolf Virchow, no século XIX, posteriormente reafirmados por Lalonde, em 1974, e mais recente por pesquisadores canadenses, destacam os Determinantes Sociais da Saúde (DSS), como a principal ferramenta para trabalhar os recursos condicionantes da saúde, sendo definidos como condições econômicas e sociais que moldam a saúde das pessoas, comunidades e territórios. ${ }^{2}$

Neste estudo, adotou-se a definição de Promoção da Saúde como o "processo de capacitação das pessoas, famílias e comunidade para atuar na melhoria de sua qualidade de vida e saúde, incluindo maior participação no controle desse processo", 1:1 e têm os DSS como principais recursos para trabalhar a melhoria das condições de saúde das famílias para exercerem maior controle sobre elas. O intuito da promoção da saúde é tornar o indivíduo protagonista da sua saúde.

No contexto brasileiro, após a criação do Sistema Único de Saúde (SUS), marcado pela luta da Reforma Sanitária e pela Constituição de 1988, deu-se início às principais mudanças nas concepções 
ampliadas de saúde na lógica da Promoção da Saúde, estabelecendo-se as principais diretrizes para a organização do componente Atenção Básica, na Rede de Atenção à Saúde (RAS). ${ }^{3}$

A Política Nacional de Atenção Básica (PNAB) e a Política Nacional de Promoção da Saúde (PNPS), têm na Saúde da Família (SF) sua estratégia prioritária para a expansão e a consolidação das intervenções de Promoção da Saúde, exercida no contexto da Atenção Primária à Saúde (APS), termo similar a Atenção Básica $(\mathrm{AB})$ no Brasil, caracterizado como uma das portas de entrada para os serviços oferecidos pelo SUS. ${ }^{3-4}$ Logo, é na APS integrada à Estratégia de Saúde da Família (ESF), que se trabalham as principais ações de Promoção da Saúde com foco nas pessoas, famílias e comunidades, além do reconhecimento dos territórios que estão inseridas, perfil populacional, indicadores de saúde e vulnerabilidades. ${ }^{3}$

De acordo com a PNAB, publicada em 2017, para que as equipes que atuam na AB possam atingir seu potencial resolutivo, de forma a garantir a coordenação do cuidado, ampliando o acesso, é necessário adotar estratégias que permitam a definição de um amplo escopo dos serviços a serem ofertados na APS, de forma que seja compatível com as necessidades e demandas de saúde da população adscrita, seja por meio da ESF ou outros arranjos de equipes de $\mathrm{AB}$, que atuem em conjunto, compartilhando o cuidado e apoiando as práticas de saúde nos territórios. Essa oferta de ações e serviços na APS devem considerar políticas e programas prioritários, as diversas realidades e necessidades dos territórios e das pessoas, em parceria com o controle social. ${ }^{3}$

Para compreender o processo de cuidado para a Promoção da Saúde sintonizado em reais necessidades das pessoas, das famílias e das comunidades emergiu a necessidade de conhecer o imaginário da Promoção da Saúde, uma vez que é no quotidiano que as imagens se apresentam, e carregadas de significados formam o nosso imaginário numa relação de retroalimentação (imagem imaginário). ${ }^{5}$ Acreditando ainda que, o real de cada um é também seu imaginário, sendo ele parte integrante da vida, entende-se que o mundo imaginal expressa uma cultura, comportamentos e valores em um determinado contexto histórico-social. ${ }^{5}$ 
O imaginário da promoção da saúde no quotidiano das famílias na atenção primária $\mid 4$

Este estudo, considerando a Promoção da Saúde parte integrante do cuidado desenvolvido na APS e que o foco de trabalho das equipes são as famílias inseridas em cada território, apresenta como questão de pesquisa: qual o imaginário da Promoção da Saúde das famílias no quotidiano da APS?

Deste modo, a relevância da Promoção da Saúde no processo de trabalho da ESF e os desafios ainda encontrados na APS acerca das atividades voltadas para o modelo preventivista. Neste modelo os profissionais de saúde atrelados ao desenvolvimento de atividades de demanda espontânea com excedentes populacionais em seus territórios encontram barreiras na execução de ações de Promoção da Saúde no seu quotidiano de trabalho. Assim, justifica-se a realização desta pesquisa, tendo em vista que as ESF precisam avançar em suas ações e colocar em prática as políticas de saúde, para isso é preciso conhecer as famílias de seus territórios e como elas percebem a Promoção da Saúde do seu dia a dia para avançarmos com novas propostas.

Com base no exposto, este estudo apresenta como objetivo: conhecer o imaginário da Promoção da Saúde das famílias no quotidiano da Atenção Primária à Saúde.

\section{Método}

Trata-se de um estudo qualitativo, descritivo e exploratório, fundamentado no referencial teórico da Sociologia Compreensiva e do Quotidiano de Michel Maffesoli, realizada em uma Unidade Básica de Saúde em um município no sul do Brasil.

Participaram da pesquisa pessoas regularmente matriculadas e integrantes de um programa municipal, que existe desde 2006, enfocando a Promoção da Saúde e Qualidade de Vida, utilizando práticas corporais orientadas por profissionais de Educação Física e ações de educação em saúde e lazer. Além das práticas corporais, esse programa realiza atividades de lazer, como passeios a pontos turísticos e eventos culturais da região, momentos de convivência entre os participantes de outros bairros, brincadeiras recreativas durante as atividades, além de aulas de artesanato por iniciativa dos próprios participantes. Assim, esse programa foi sugerido como integrante do cenário para a pesquisa, por contemplar a proposta do estudo. 
Foram convidados a participar da pesquisa todos os integrantes do programa em questão, porém, foram excluídos os participantes que estavam afastados, por atestado médico, totalizando 19 participantes na pesquisa.

No momento da coleta estavam matriculados 25 alunos, porém dois estavam afastados por problema de saúde dois não manifestaram interesse em participar do estudo e outros dois estavam viajando no período. Do total de 19 participantes, 18 eram mulheres e um era homem, na faixa etária entre 35 e 81 anos. No que se refere à ocupação e profissão, 12 pessoas se identificaram como sendo do lar, quatro aposentados, uma Agente Comunitária de Saúde, uma faxineira e um marceneiro. Estas ocupações permitiam disponibilidade de horário para a realização das atividades.

Vale ressaltar que neste estudo, considera-se a família como uma unidade de cuidado dinâmica capaz de promover a saúde de seus membros a partir do seu quotidiano, nas diferentes etapas e mudanças do seu ciclo vital. É no ambiente interno e externo que a Promoção da Saúde se expressa, a partir das relações e interações familiares com seus membros e destes com o contexto mais amplo de suas relações como a sociedade, comunidade, vizinhança, amigos, serviços de saúde e demais instituições, as políticas públicas, entre outros. ${ }^{6}$ Assim, o grupo formado por este programa é uma família formada por elos de amizade e afinidade.

A coleta de dados foi realizada de agosto a novembro de 2015, a partir de entrevistas semiestruturadas grupais com perguntas abertas, adotando como estratégia de coleta de dados uma oficina, baseada no Projeto Ninho. ${ }^{7}$ A estratégia da oficina possibilita um momento interativo e recreativo para as pessoas, tornando a entrevista semiestruturada mais dinâmica. Esta estratégia já foi validada por outros estudos ${ }^{7-9}$ Ela apresenta quatro momentos: Relaxamento de Acolhimento, Atividade Central, Conjunção e Relaxamento de despedida. ${ }^{7}$

No momento Relaxamento e Acolhimento, foi disponibilizada, pela pesquisadora, uma música para alongamento e apresentação dos participantes, tornando o ambiente acolhedor. Na Atividade Central foram realizadas atividades visando fortalecer o grupo, direcionando os participantes a refletir sobre sua saúde. Foi lançada a questão norteadora: “O que é Promoção da Saúde para você?” Na etapa da conjunção, houve reflexão e discussão, realizando uma integração entre as diferentes perspectivas dos 
O imaginário da promoção da saúde no quotidiano das famílias na atenção primária 6

participantes. Na última etapa, nomeada relaxamento, houve música e alongamento com posterior conclusão da discussão.

Foram organizadas três oficinas, com 5 ou 6 participantes em cada uma. Os grupos foram pequenos com objetivo de possibilitar maior diálogo e participação de todos os participantes. Cada oficina teve duração média de uma hora e meia.

O registro dos dados foi realizado por meio de anotações feitas após cada entrevista para construção de Diário de Campo, com intuito de auxiliar na sustentação da análise e interpretação dos dados. $^{7}$ As entrevistas foram gravadas em modo digital e transcritas na íntegra em formato Word pela pesquisadora responsável pelo estudo.

Após o registro, as entrevistas foram organizadas e categorizadas pelo software Atlas.TI versão 6.1, a análise dos dados, sustentada por Schatzman e Strauss, e tendo como fio condutor o olhar à luz do referencial teórico da Sociologia Compreensiva e do Quotidiano de Michel Maffesoli, buscou-se conectar as ligações das classes e as ideias centrais criando categorias e subcategorias, agrupadas conforme o objetivo do estudo. ${ }^{10}$ Após análise exaustiva dos dados, o estudo chegou à análise e discussão final trazendo suas conclusões e considerações conforme seu objetivo com elementos que pudessem ampliar e contribuir para a temática estudada, constituindo quatro categorias.

Atendendo à garantia do sigilo das identidades dos participantes, para a apresentação dos relatos, cada participante escolheu o nome de uma flor para ser representado na pesquisa. Os aspectos éticos foram respeitados, sendo que esta pesquisa foi aprovada pelo Comitê de Ética sob o protocolo de n $^{\circ}$ 45932915.0.0000.0121 na data de 13/07/2015. Os participantes do estudo assinaram o Termo de Consentimento Livre Esclarecido, preconizado pela Resolução nº 466/2012 do Conselho Nacional de Saúde do Ministério da Saúde. ${ }^{11}$ 


\section{Resultados e discussão}

As quatro categorias que emergiram no processo de análise foram: Buscar saúde no quotidiano; Priorizar e Promover uma melhor qualidade de vida; Fragilidades da promoção da saúde no quotidiano do SUS; e Potencialidades da promoção da saúde no quotidiano do SUS.

\section{Buscar Saúde no Quotidiano}

A Promoção da Saúde mostrou-se como um buscar saúde no quotidiano. O buscar foi apresentando em vários momentos nas falas das pessoas e perpassou por outras categorias como algo significativo para a Promoção da Saúde, conforme os relatos:

Eu acho que é buscar de várias formas que a gente tenha uma saúde melhor. Não só na questão do posto, mas a gente buscar no próprio dia a dia. É fazer uma caminhada, pensar coisas boas, ter contato com outras pessoas, porque acho que isso é o que convém mais. A união das pessoas, o conviver com as pessoas, porque a gente sozinho não é ninguém. (Violeta)

A Promoção da Saúde é algo a se buscar, e esta busca vai além das questões que envolvem os serviços de saúde, ela se dá no próprio dia a dia. Maffesolii ${ }^{12}$ afirma que o quotidiano é onde as pessoas mostram seus estilos de vida, seus pensamentos, sua ética com base nas experiências e nas tribos às quais pertencem, indo ao encontro da fala que é mencionada na qual o buscar a saúde no quotidiano se dá a partir de uma caminhada, pensar coisas boas, conviver com as pessoas, pois isso é mais conveniente, remetendo a Promoção da Saúde como a maneira de viver que se expressa no dia a dia.

Ainda, o imaginário em que mergulha a socialidade contemporânea se vive no quotidiano, e é neste quotidiano anódino, frívolo, o que a priori não é levado em consideração pelas instituições, que se constrói o terreno no qual podem crescer e se fortalecer as novas maneiras de ser e pensar, o que ele chama de potência societal. ${ }^{12}$

Ela também vai ao encontro da noção de saúde ampliada que se tem trabalhado na perspectiva da Promoção da Saúde que é possível reconhecer a natureza complexa, interdisciplinar e intersetorial das 
O imaginário da promoção da saúde no quotidiano das famílias na atenção primária $\mid 8$

práticas de saúde, reafirmando que os problemas de saúde não se esgota no uso de tecnologia médica ou na mudança de comportamento individuais. ${ }^{13}$

Em outro momento, quando se indaga o que é Promoção da Saúde, aparece o significado de saúde:

Saúde para mim começa pela higiene em casa. Uma boa limpeza de banheiro, é um banho adequado, ou a comida sempre tampada, evitando mosca, tudo cobertinho [...] é uma composição de muitas coisas que a gente pode buscar e, às vezes, está dentro da saúde e a pessoa não percebe. (Bromélia)

Este depoimento nos remete a uma noção de saúde que expressa o Modelo Higienista. Esta perspectiva, egressa do século XIX suscita a mudança dos hábitos de higiene enquanto normas e recomendações para obter saúde, sem considerar os DSS. Esses determinantes são fatores sociais, econômicos, culturais, étnicos, psicológicos e comportamentais que influenciam a ocorrência de problemas de saúde, simplificando o processo saúde e doença como fenômeno intrínseco ao biológico. ${ }^{14}$

Entretanto, respaldando esta análise, um estudo,${ }^{15}$ sobre a percepção dos usuários da ESF acerca de suas concepções de saúde, mostrou que a saúde não é apenas a ausência de doenças, é condição para manutenção da vida, resultante da interação de fatores, de condições e hábitos de vida, sendo influenciada pela ocupação e pelas interações cotidianas e sociais, opondo-se a visão biologicista.

O imaginário dos participantes deste estudo nos aponta um movimento de aproximação e distanciamento ao significarem Promoção da Saúde e Saúde:

[...] promoção é uma coisa que eu vou buscar para melhorar a minha saúde. As palestras que tem aqui, eu participo, que eu vou entender melhor. E a saúde eu tenho que buscar em casa; em casa eu tenho que tomar meu medicamento no horário certo, me alimentar adequadamente. E promoção tudo que você vai, "ah hoje tem uma palestra lá” aquilo ali é uma promoção; eu vou lá aprender mais, buscar entendimento. (Bromélia)

Nesta fala, a palavra promoção, originada do latim promotio, onis, promoção, ato ou efeito de promover, é mencionada como algo positivo a se buscar para melhorar a saúde, algo que vem de fora, externo, sendo ligado à educação, a aprender, como por exemplo, as palestras na unidade de saúde. Porém a saúde que se busca em casa é mencionada dentro de uma noção do modelo reducionista, 
apontando apenas a mudança de comportamento, respaldada pela força do instituído imposta pela sociedade, da lógica do dever ser. ${ }^{16}$

A busca para melhorar a saúde, a partir da participação das pessoas em atividades de Promoção da Saúde, é apoiada nos campos de ação da Carta de Ottawa caracterizados como desenvolvimento de habilidades pessoais, bem como de participação popular. O desenvolvimento de habilidades pessoais apoia tanto a dimensão pessoal quanto social por meio da divulgação, informação, educação para a saúde e intensificação das habilidades vitais para que as pessoas tenham mais opções de escolha e controle sobre sua própria saúde e sobre o meio ambiente. ${ }^{1}$

Um estudo sobre a utilização de práticas corporais e meditativas na Promoção da Saúde na APS, identificou a construção de referências próprias de saúde, e a potencialização de mudanças no modo dessas pessoas se relacionarem com os eventos da vida, o que corrobora a importância da promoção da saúde no contexto da APS. ${ }^{17}$ Portanto, pensar na promoção da saúde da família é também proporcionar estes espaços para que tenham um melhor conviver e ser saudável.

Assim, torna-se um recurso para trabalhar a saúde das pessoas, da família e da comunidade nos diversos espaços onde estão inseridas, inclusive na ESF, a partir de estratégias participativas, que vão além do modelo de educação tradicional, promovendo o diálogo, reflexão e consciência crítica para atuarem na melhoria de sua vida, ou seja, reforçando um pensamento libertário que nutra a potência de cada um.

\section{Priorizar e promover uma melhor qualidade de vida}

Também é mencionado que a Promoção da Saúde é vinculada à qualidade de vida. O ato de promover, dar impulso ou pôr em execução representa uma ação positiva para a Promoção da Saúde. E a prioridade do latim prioritas, primeiro, garantir prioridade, apontada também para melhorar a qualidade de vida vai ao encontro do conceito de Promoção da Saúde da Carta de Ottawa. ${ }^{1}$

Porém, para os entrevistados, a prioridade para se ter uma melhor qualidade de vida aparece limitada à atividade física, alimentação, o controle do peso, retomando o olhar reducionista restringindo 
à mudança de comportamento as questões que envolvem o processo de capacitação das pessoas para a Promoção da Saúde.

Promoção da saúde é promover ou ter uma melhor qualidade de vida. É o que prioriza. Priorizar uma melhor qualidade de vida. Pode ser com atividade física ou alimentação. (Azaléia)

[...] para não comer demais depois que faz a atividade. Chegar em casa e não comer para controlar o peso. (Anis)

Segundo a Carta de Ottawa, o processo de capacitação tem como foco alcançar as equidades em saúde:

As ações de promoção da saúde objetivam reduzir as diferenças no estado de saúde da população e assegurar oportunidades e recursos igualitários para capacitar todas as pessoas a realizar completamente seu potencial de saúde. Isto inclui uma base sólida: ambientes favoráveis, acesso à informação, a experiências e habilidades na vida, bem como oportunidades que permitam fazer escolhas por uma vida mais sadia. ${ }^{1: 1}$

Embora os entrevistados consideram prioritariamente a Promoção da Saúde como controlar a alimentação e atividade física, é importante ressaltar que proporcionar o acesso aos recursos supracitados é de fato promover a saúde.

\section{Fragilidades da Promoção da Saúde no quotidiano do SUS}

Durante a entrevista, os familiares remeteram à situações quotidianas para exemplificar a Promoção da Saúde no seu dia a dia. Após emergir a categoria "Priorizar e promover uma melhor qualidade de vida”, os participantes trouxeram questões que demonstram as fragilidades enfrentadas no quotidiano no SUS que implicam na concretização da Promoção da Saúde.

Eu fui fazer um exame pelo SUS, o meu está demorando seis meses na espera. Tem colega meu que demora mais de um ano. Quer dizer, se depender do SUS, morre. (Lavanda)

Se a gente depender do SUS, só do SUS temos que ficar calmos e ficar esperando. (Hibisco) 
O imaginário da promoção da saúde nos traz uma realidade na qual a dependência da pessoa para a realização de um exame no SUS expressa uma espera que pode levar a morte, caso não tenha condições de recorrer a outro serviço de saúde. Por outro lado, para depender só do SUS "tem que” ficar calmo, “tem que” ficar esperando, retornando à lógica do “dever ser”! Este “tem que” remete ao que é instituído e normativo pela instituição ou pela sociedade, não apontando o conhecimento de seus direitos e deveres enquanto usuário do SUS. Um estudo sobre a busca pelo sistema de justiça entre usuários do SUS, demonstrou que a apreensão do brasileiro com a demora no atendimento no SUS é um problema de saúde pública. ${ }^{18}$

O imaginário das fragilidades da Promoção da Saúde no quotidiano do SUS demonstra certa impotência apontada a partir da insatisfação e a falta da manifestação popular em busca de melhores condições de saúde:

Se eu brigar lá. Adianta alguma coisa?(Hibisco)

[...] não reclamar no posto de saúde, porque aqui no posto eles não têm culpa, eles são mandados. (Lótus)

De repente o povo quer, mas quem entra lá não faz. (Hibisco)

Existem evidências que o perfil de usuários que buscaram orientação jurídica para a resolução de seus problemas no SUS, é o do cidadão que está a espera de um procedimento entre 1 e 7 anos. ${ }^{18}$

O investimento na saúde também surgiu no imaginário ao se buscar o significado de Promoção da Saúde:

\section{Tem que investir mais na saúde. (Lavanda)}

“Tem que” é uma condição, da ordem do “dever ser”, enquanto investir é da ordem do empregar (dinheiro, tempo ou esforço). O Ministério da Saúde tem investido na reestruturação e reorientação do modelo de APS do Brasil, inicialmente com a criação da ESF, ampliação de equipes de profissionais, infraestrutura, pesquisas e comunicação, e todo o processo que envolve o serviço com objetivo de uma melhor saúde para as pessoas, as famílias e a comunidade. Entretanto, o recurso e esforço destinado ao SUS é um dos impasses gerenciais do sistema que se reflete, na maioria das vezes, negativamente no dia 
a dia das pessoas que buscam e acreditam nos princípios e diretrizes do serviço, e que ainda, não possui critérios de eficiência temporal para atendimentos eletivos. ${ }^{18}$

Este "ter que” nos faz repensar que talvez o caminho não seja pela via do "dever ser”, levando-nos a questionar se caminhar pela via do "ser preciso", que expressa as reais necessidades, não seria mais efetivo e resolutivo.

O quotidiano, ou seja, a maneira de vivenciarem o SUS é percebido pelas pessoas em relação ao serviço oferecido em outros níveis de atenção, apontando negativamente as experiências vivenciadas, como descrito nas falas sobre o descaso dos profissionais no atendimento, que por muitas vezes ficam no conforto ou mesmo no consultório realizando outras atividades ao invés e atender as demandas da assistência.

Igual ali na UPA [Unidade de Pronto Atendimento]. Você vai ali olha lá dentro o médico está lendo, dormindo. Minha filha ficou lá de manhã até meio dia, e veio embora para casa sem ser atendida. Porque eles não estão nem aí com a gente, eles acham que a pessoa chegou lá andando está bem. Mas, às vezes está morrendo. (Lótus)

Está no Whatsapp. Eu já peguei, estava esperando, esperando, entrei de fininho e estava lá. (Íris)

A presença do Whatsapp chama atenção dentre os meios de comunicação utilizados no horário de trabalho pelos profissionais, remetendo-nos a força da tecnosocialidade na contemporaneidade. Para Maffesoli, a característica da pós-modernidade é a sinergia entre o arcaico e desenvolvimento tecnológico, em que estes meios de comunicação próprios da internet estão criando novas formas de ser, de trocar, a estrutura do vínculo social. ${ }^{10}$

Estas falas também remetem a Reorientação dos Serviços de Saúde, campo de ação da Carta de Ottawa, a qual apoia os serviços a adotarem uma postura abrangente, que perceba e respeite as peculiaridades culturais e necessidades individuais das pessoas, famílias e comunidade, para uma vida mais saudável, abrindo canais entre o setor saúde e os setores sociais, políticos, econômicos e ambientais. ${ }^{1}$

Potencialidades da Promoção da Saúde no quotidiano do SUS 
Por outro lado, o quotidiano que envolve a Promoção da Saúde, decorrente das interações em um grupo de promoção da saúde, é significado como uma experiência que contribui para melhorar o dia a dia das pessoas, contribuindo para um ser saudável.

antes eu acordava de manhã e dizia que não iria mais à atividade. Porque quando eu comecei a frequentar a atividade eu tinha dor no joelho. Depois, eu continuei indo sem parar. Aí sarou todas as dores. (Anis)

Esta fala menciona o antes e o depois da inserção em um grupo de promoção da saúde, apontando melhora na saúde física após a realização das atividades no grupo.

Ao ser indagado “como o momento que você vivencia aqui influencia no seu dia a dia?” mais da metade dos participantes afirmam que o momento vivenciado nas atividades influenciam positivamente no dia a dia deles, além de apontarem mudanças na maneira de ver e pensar a Promoção da Saúde:

Você tem um propósito. Não é só vir aqui caminhar. Qualquer um deles dá a dica de como é que você pode ter uma saúde. E vai depender de você querer seguir para frente. Eu comecei por aqui. Porque com cinquenta e quatro anos eu não caminhava daqui à padaria, andava de moto, de carro. Hoje eu faço caminhada longa, então graças a Deus. Começou aqui. Eles me deram a dica de como eu poderia ter uma saúde mais tranquila. Eu levei isso para dentro de casa, meus filhos acataram também. Então o grupo e a Academia para mim é tudo. (Lavanda)

A força da tribo é apontada nesta fala e as atividades em grupo reforçam o trabalho para a Promoção da Saúde, visto que o grupo fortalece e mobiliza as famílias para promoverem saúde no seu dia a dia. Para Michel Mafessoli a tribo é como uma família, um grupo de pessoas que estabelecem interesses em comum, conformidade de pensamentos, hábitos de vida podendo se fortalecer nesse convívio do dia a dia. ${ }^{12}$

A Promoção da Saúde também é apontada como sujeito do próprio cuidado, visto que a família se empodera construindo recursos próprios, como exemplo atividade física:

O pai e a mãe também tinham que incentivar um pouco. O meu genro, não vai buscar pão que é 50 metros se não for de carro. E o filho não vai comprar uma borracha caminhando "Ô pai, vamos de carro?". Esses dias eu disse assim, "vão caminhar! A vó caminha por tudo”. Eles não fazem nada, nada, nada. Só ficam naquele "tcheque tcheque tcheque tcheque tcheque" $E$ vinte e quatro horas por dia. Eu levanto às três da manhã pra ir no banheiro eles tão lá "tcheque tcheque tcheque tcheque tcheque [vídeo game]. (Hibisco) 
O imaginário da promoção da saúde no quotidiano das famílias na atenção primária | 14

Eu sou dançarina, mas também é uma academia. O médico falou para mim que dançar é uma academia. (Alecrim)

É importante ressaltar que a mudança de comportamento pode ter relação com a atividade física, pois é a principal característica do grupo que eles participam, sendo o principal desafio das atividades que caracterizam a temática da Promoção da Saúde desenvolver ações para além da mudança de comportamento.

Esta realidade pode ser reflexo de quem executa as atividades, pois estudos que investigaram a percepção de profissionais da ESF acerca da Promoção da Saúde afirmam que existe uma incoerência da percepção dos profissionais com o discurso e a prática; os cuidados realizados são em sua maioria com foco na prevenção e monitoramento da doença; e o desenvolvimento das ações de Promoção da Saúde está em construção..$^{16-17}$

As pessoas trazem o imaginário da força da coletividade enquanto forma de organização e manifestação, e apresenta a união das pessoas como possibilidade de mudança no contexto da saúde do país:

Se eu chamar ninguém vai. Todo mundo quer, mas ninguém vai reclamar. Porque seria tipo a união. Todo mundo. Não ir brigar para o que não resolve. Então não adianta, tem que ter paciência, ficar esperando até chamar. Todo mundo! [...] tinham que reclamar para os grandões, todo mundo, mas não um só ou um ou dois só. [...] tem que se reunir. (Lótus)

Toda comunidade. Cada bairro reunir sua comunidade. (Hibisco)

Mas a cada quatro anos o povo se reuni. É só saber ser organizar. (Lavanda)

Tem que se reunir [...] Nós queremos melhorar isso, isso e isso. É o que nós queremos!(Lótus)

As falas mencionadas apontam as manifestações das pessoas por quererem melhoria na saúde, porém o "tem que" novamente aparece representando uma condição da ordem do "dever ser" instituído, seguido da ideia de coletividade (todo mundo, união das pessoas) para concretizarem suas vontades. Esta necessidade de se reunir, de estar junto, representa o ideal de se viver em uma comunidade, é uma 
potência coletiva que não se reconhece mais no artificialismo contratual, mas que se conforta sobre o consentimento natural. É a ética da estética, isto é, um elo que se elabora a partir de um sentimento coletivo. ${ }^{12}$

É importante ressaltar que, no contexto atual o país está passando por uma crise econômica, política e ambiental que tem refletido concreta e simbolicamente nas questões da saúde. Maffesoli ${ }^{12}$ refere que sempre houve uma relação significante entre o retorno do trágico e a exaltação vital, e é neste momento do vivido atual que existe o ideal comunitário, que está na ordem do dia, no papel aumentado da experiência e destaca o retorno com força do apetite de viver.

Neste cenário, vale ressaltar que a Promoção da Saúde também trabalha o Reforço da Ação Comunitária:

[...] através de ações comunitárias concretas e efetivas no desenvolvimento das prioridades, na tomada de decisão, na definição de estratégias e na sua implementação, visando à melhoria das condições de saúde. O centro deste processo é o incremento do poder das comunidades - a posse e o controle dos seus próprios esforços e destino. ${ }^{1: 3}$

O reforço da ação comunitária, ou seja, da participação popular, expressas no Controle Social também está nos princípios e diretrizes do SUS, estabelecida e regulada pela lei $8.142 / 90,{ }^{19}$ a partir da inclusão dos atores sociais nos processos decisórios da política de saúde do país. Assim, a lei estabelece a criação de Conselhos de Saúde e Conferências de Saúde, nas três esferas de governo, bem como de colegiados de gestão nos serviços de saúde.

Entretanto, desenvolver a participação da comunidade no dia a dia dos serviços envolvendo as pessoas, as famílias e a comunidade nas ações coletivas, é um dos desafios do SUS. Pois ela se dá nas ações de lazer e convivência, desvelando e valorizando saberes e experiências existentes como potencialidades da realidade que segue em permanente construção. ${ }^{20}$

Infelizmente na APS a integração assistencial não é realmente efetiva, e nem o fornecimento de cuidados integrais com qualidade. ${ }^{20} \mathrm{~A}$ consequência é que apesar de constitucionalmente garantido, na prática, o direito à saúde ainda é um dos desafios do sistema de saúde. 
O imaginário da promoção da saúde no quotidiano das famílias na atenção primária | 16

É assim que a situação de: “Uma andorinha sozinha....” (Íris) se transfigura, mais uma vez, expressando a potência, a força que vem de dentro de cada pessoa, resgatando o empowerment de cada família, de cada comunidade, entrelaçadas pela ética da estética, ou seja, de um sentir junto!

É evidente que a Promoção da Saúde perpassa as intervenções verticalizadas centrada na prevenção e controle de doenças e na mudança de comportamento individuais, assim torna-se crucial a crítica reflexiva sobre os modos de vida integrada às mudanças institucionais para atingir resultados mais efetivos acerca das práticas da Promoção da Saúde no quotidiano da APS. ${ }^{13}$

\section{Conclusão}

Ao final deste estudo foi possível compreender, por meio do imaginário das famílias, a Promoção da Saúde como algo a ser alcançado pelas pessoas e que se dá no quotidiano, envolvendo pensar coisas boas, estar com as pessoas, fazer uma caminhada, alimentar-se bem, não comer demais, higiene da casa, buscar entendimento para ter uma saúde melhor, além de perpassar pelas experiências vividas no quotidiano do SUS do Brasil.

Deste modo, os resultados mostraram que a Promoção da Saúde ainda remete ao reducionismo por trazer a mudança de comportamento e não expandir as questões de saúde para além do setor saúde e de um estilo de vida, não reconhecendo os DSS como fatores de mudança. Em contrapartida, os participantes descrevem a vontade de se reunir e se manifestar em busca de seus direitos, enquanto cidadãos e usuários do SUS, apontando um imaginário onde a potência trazida pelo sentido comunitário, intrínseco a sua natureza humana, se manifesta quando é oportunizado o encontro trazido pela ética e a estética.

Como limitações, considera-se a definição dos participantes da pesquisa, uma vez que existem poucos grupos que trabalham com olhar da promoção da saúde. Nesse sentido, este estudo deixa uma provocação aos serviços de saúde sobre de que forma a promoção a saúde pode ser implementada de modo a impactar com maior intensidade sobre as condições de vida quotidianas e os determinantes sociais de saúde. 
Como contribuições para e enfermagem, destaca-se, ainda, a Promoção da Saúde como parte integrante do cuidado da enfermagem familial, e a importância do papel do Enfermeiro em valorizar, fortalecer e exercer ações que promovam a participação das pessoas, famílias e comunidade em seus diferentes contextos sociais e culturais, respeitando a individualidade das pessoas e núcleo familial, criando estratégias criativas e dialógicas neste processo de construção coletiva, com o objetivo de proporcionar condições para um quotidiano de saúde e vida digna para a população.

Faz-se necessária a realização de novas investigações que compreendam o imaginário da Promoção da Saúde no contexto da APS, a fim de explorarem e conhecerem outras realidades e atividades desenvolvidas, e contribuir para o fortalecimento de ações e cuidados para a Promoção da Saúde na ESF, promovendo, desta forma, mais autonomia das pessoas e suas famílias.

\section{Referências}

1. World Health Organization. Ottawa charter for health promotion. Ottawa: WHO [Internet]. 1986. [acesso em 10 jan 2018]. Disponível em: $<$ http://www.who.int/healthpromotion/conferences/previous/ottawa/en/ >.

2. Rootman I, O’neilL M. The Evolution of Health Promotion Practice. In: Dupéré S, Pederson A, O'Neill M, editors. Perspectives on Health Promotion from Different Areas of Practice. 3rd ed. Toronto: Canadian Scholar's; 2012. p. 266-90.

3. Brasil. Portaria n 2.436, de 21 de setembro 2017. Aprova a Política Nacional de Atenção Básica (PNAB) [Internet]. Brasília (DF). 2017. [acesso em 08 mar 18] Disponível em: http://bvsms.saude.gov.br/bvs/saudelegis/gm/2017/prt2436_22_09_2017.html

4. Brasil, Portaria no 2.446, de 11 de novembro de 2014. Redefine a Política Nacional de Promoção da Saúde (PNPS) [Internet]. 2014. [acesso em 12 mar 2018]. Disponível em: http://bvsms.saude.gov.br/bvs/saudelegis/gm/2014/prt2446_11_11_2014.html

5. Prado RA et al. O Quotidiano e o Imaginário no Processo Saúde-Doença para as Famílias Quilombolas. Saúde Transform. Soc. [Internet]. 2013. [acesso em 02 ago 2018], 4(4): 47-53. Disponível em: http://pepsic.bvsalud.org/scielo.php?script=sci_arttext\&pid=S2178-70852013000400009.

6. Fernandes GCM. Rotinas e rituais de cuidado nas famílias rurais em transição inesperada do pósdesastre [tese] Florianópolis: Universidade Federal de Santa Catarina; 2011. 
7. Tholl AD. O quotidiano e o ritmo de vida de pessoas com lesão medular e suas famílias: potências e limites na adesão à reabilitação para a promoção da saúde [tese]. Florianópolis: Universidade Federal de Santa Catarina; 2015.

8. Michelin, SR. O Quotidiano Laboral e Familial dos trabalhadores da Atenção Primária: Potências e Limites para a Promoção da Saúde [tese]. Florianópolis: Universidade Federal de Santa Catarina; 2019.

9. Nóbrega JF. O Imaginário da Promoção da Saúde no Quotidiano da Formação do Técnico em Enfermagem [dissertação]. Florianópolis: Universidade Federal de Santa Catarina; 2012.

10. Nistchke RG et al. Contribuições do pensamento de Michel Maffesoli para pesquisa em enfermagem e saúde. Texto contexto - enferm. [Internet]. 2017. [acesso em 02 ago 2018], 26(4): 1-12. Disponível em: http://www.scielo.br/pdf/tce/v26n4/0104-0707-tce-26-04-e3230017.pdf.

11. Ministério da Saúde (BR). Resolução № 466, de 12 de dezembro de 2012. Aprova as diretrizes e normas regulamentadoras de pesquisas envolvendo seres humanos [Internet]. Brasília (DF) Ed do MS, 2012. [acesso em 12 jan 2016]; Disponível em: <http://conselho.saude.gov.br/resolucoes/2012/Reso466.pdf. Acessado em: 13 de jan. De 2015.

12. Maffesoli, M. Homo Eroticus: comunhões emocionais. 1 ed. Rio de Janeiro: Forense Universitária, 2014.

13. Tavares, MFL et al. Promoção da Saúde e o Desafio da Intersetorialidade na Atenção Básica do Brasil. In: Maria Helena Magalhães de Mendonça (Org.). Atenção Primária à Saúde no Brasil: conceitos, práticas e pesquisa. Rio de Janeiro: Fiocruz, 2018. Cap. 6. p. 177-196.

14. Kleba ME. Reforço da Ação Comunitária. Florianópolis: UFSC, 18 nov. 2015. Palestra ministrada no I Simpósio Internacional de Promoção da Saúde: diálogo com os determinantes sociais.

15. Budo MLD, Schimith MD, Garcia RP, Seiffert MA, Simon BS, Silva FM. Concepções de Saúde de Usuários e Profissionais de uma Estratégia de Saúde da Família. Rev Enferm UFSM [internet]. 2014. [acesso em 10 jan 2018] 4(2):439-449. Disponível em: https://periodicos.ufsm.br/reufsm/article/view/10461/pdf

16. Heidemann ITSB. Wosny AM Boehs AE. Promoção da Saúde na Atenção Básica: estudo baseado no método de Paulo Freire. Cien Saude Colet [Internet]. 2014. [acesso em 11 jul 2018]; 19(8):3553-3559. Disponível em: http://www.scielo.br/pdf/csc/v19n8/1413-8123-csc-19-08-03553.pdf

17. Galvanese ATC, Barros NF, d'Oliveira AFPL. Contribuições e desafios das práticas corporais e meditativas à promoção da saúde na rede pública de atenção primária do Município de São Paulo, Brasil. Cad Saúde Pública [Internet]. 2017. [acesso em 23 fev 2018]; 33(12): Disponível em: http://www.scielo.br/scielo.php?script=sci_arttext\&pid=S0102-311X2017001205001\&lng=en. Epub Dec 18, 2017. 
19 I Costa JC, Nitschke RG, Rocha PFA, Andrade BB

18. Freitas, FR.; Sant'ana, NR. Direito fundamental à saúde no SUS e a demora no atendimento em cirurgias eletivas. RDU, Porto Alegre, vol 12, n.67, 2016.

19. Brasil. Lei no 8.142, de 28 de dezembro de 1990. Dispõe sobre a participação da comunidade na gestão do Sistema Único de Saúde (SUS) e sobre as transferências intergovernamentais de recursos financeiros na área da saúde e dá outras providências [Internet]. Brasília (DF) 1990. [acesso em 02 fev 2018]. Disponível em: http://conselho.saude.gov.br/legislacao/lei8142_281290.htm.

20. Giovanella L, Almeida PF. Atenção primária integral e sistemas segmentados de saúde na América do Sul. Cad Saúde Pública [Internet]. 2017 [acesso em 23 fev 2018]; 33( Suppl 2 ): e00118816. Disponível em: http://www.scielo.br/scielo.php?script=sci_arttext\&pid=S0102-311X2017001405005\&lng=pt. Epub02-Out2017.

\section{Autor correspondente}

Nome: Juliana Chaves Costa

E-mail: julianachavescosta@gmail.com

Endereço: Rua 3144,188, ap 603, Centro, Balneário Camboriú, SC.

CEP: 88330-296

\section{Contribuições de Autoria}

1 - Juliana Chaves Costa

Concepção e planejamento do projeto de pesquisa, obtenção, análise e interpretação dos dados, redação e revisão crítica.

2 - Rosane Goncalves Nitschke

Concepção e planejamento do projeto de pesquisa, análise e interpretação dos dados, revisão crítica.

3 - Patrícia Fernandes Albeirice da Rocha

Análise e interpretação dos dados, revisão crítica.

3 - Betina Barbedo Andrade

Análise e interpretação dos dados, revisão crítica.

\section{Como citar este artigo}

Costa JC, Nitschke RG, Rocha PFA, Andrade BB. O imaginário da promoção da saúde no quotidiano das famílias na atenção primária. Rev. Enferm. UFSM. 2019 [Acesso em: Anos Mês Dia];vol e65: 1-19. DOI:https://doi.org/10.5902/2179769233603 